\title{
Superselective internal iliac arterial embolization for severe hemorrhage following radical prostatectomy
}

\author{
SHENG CHENG, LIWEI XU, GONGHUI LI, YUEBING CHEN, HONGJIE HU, \\ ZHIGEN ZHANG and GUOQING DING \\ Department of Urology, Sir Run Run Shaw Hospital, College of Medical Sciences, \\ Zhejiang University, Hangzhou, Zhejiang 310016, P.R. China
}

Received February 24, 2012; Accepted May 24, 2012

DOI: $10.3892 / \mathrm{ol} .2012 .749$

\begin{abstract}
Severe hemorrhage following a prostatectomy is a rare and serious complication. A 63-year-old male with severe hemorrhage following radical prostatectomy which led to hypovolemic shock presented at our department and was treated with superselective internal iliac arterial embolization. At 6 months follow-up, the patient had recovered well, regained excellent urinary continence and the pelvic hematoma was absorbed using ultrasound examination. We concluded that rapid diagnosis by computed tomography angiography and early superselective embolization of internal iliac artery should be considered as the treatment of choice in severe hemorrhage cases following radical prostatectomy.
\end{abstract}

\section{Introduction}

In Europe and America, prostate cancer is the most common type of cancer diagnosed and is the second leading cause of mortality in male cancer patients. In China, prostate cancer is the most rapidly increasing type of cancer in males, which has led to the widespread prostate-specific antigen (PSA) testing and prostate biopsy. Radical prostatectomy is the standard treatment used to cure prostate cancer. Severe hemorrhage following prostatectomy is a rare and serious complication. In a number of patients bleeding cannot be adequately controlled by conservative measures, including continuous bladder irrigation, balloon catheter traction or intermittent blood transfusion. In this study, we report a case in which superselective internal iliac arterial embolization was used for the minimally invasive management of severe hemorrhage following radical prostatectomy.

Correspondence to: Dr Guoqing Ding, Department of Urology, Sir Run Run Shaw Hospital, College of Medical Sciences, Zhejiang University, Hangzhou, Zhejiang 310016, P.R. China E-mail: guoqingding_2011@163.com; urology1978@hotmail.com

Key words: embolization, internal iliac arterial, hemorrhage, prostate, therapeutic

\section{Case report}

A 63-year-old male with a serum PSA concentration of $9.0 \mathrm{ng} / \mathrm{ml}$ underwent successful suprapubic radical prostatectomy for clinical stage T1c prostate cancer (Gleason score, $3+3$ ). The operative time was $130 \mathrm{~min}$ and the blood loss during the procedure was $300 \mathrm{ml}$ without transfusion.

Within the first 7 days following surgery, the patient recovered well without experiencing postoperative bleeding or urine leakage. However, on the eighth postoperative day, the patient suffered from excessive hematuria and bloody output from the pelvic drain following defecation. This bleeding was not controlled by conservative management methods, including continuous bladder irrigation and balloon catheter traction. In this period, the patient's hemoglobin was $6.9 \mathrm{~g} / \mathrm{dl}$, hematocrit level was $19.9 \%$, blood pressure (bp) was $85 / 55 \mathrm{mmHg}$ and pulse rate was 110 beats per min (bpm). Following a large transfusion (4 units of blood, $400 \mathrm{ml}$ of human plasma), the patient's hemoglobin was $6.3 \mathrm{~g} / \mathrm{dl}$, hematocrit level decreased to $17.6 \%$, bp was $85 / 55 \mathrm{mmHg}$ and pulse rate was $110 \mathrm{bpm}$. However, large transfusions were unable to replace the patient's blood loss and hypovolemic shock was unavoidable.

Computed tomography angiography (CTA) identified a large pelvic hematoma and active bleeding sites close to the urethrovesical anastomosis (Fig. 1). Digital subtraction angiography (DSA) of the lower abdominal aorta was conducted via a transfemoral approach using a angiographic catheter (5 Fr) and revealed contrast extravasation from branches of the bilateral internal iliac artery (Fig. 2). Superselective angiography of the internal iliac artery was used to further confirm the bleeding sites (Fig. 3). Using a microcatheter tracker $(2.5 \mathrm{Fr})$ with a guidewire (0.014 inch), superselective embolization was conducted using different sized microcoils $(5 \mathrm{~mm} \times 5 \mathrm{~cm} \times 2,2 \mathrm{~mm} \times 3 \mathrm{~cm} \times 2$ for 2 arterial branches derived from the left internal iliac artery; $2 \mathrm{~mm} \times 3 \mathrm{~cm} \times 2,3 \mathrm{~mm} \times 3 \mathrm{~cm} \times 2$ and $4 \mathrm{~mm} \times 3 \mathrm{~cm} \times 2$ for 3 arterial branches derived from the right internal iliac artery) (Fig. 4).

The procedure was successful as there were no post-procedure complications or further bleeding. The hemoglobin and hematocrit levels remained stable and the patient was discharged on the 14th postoperative day. At 6 months 


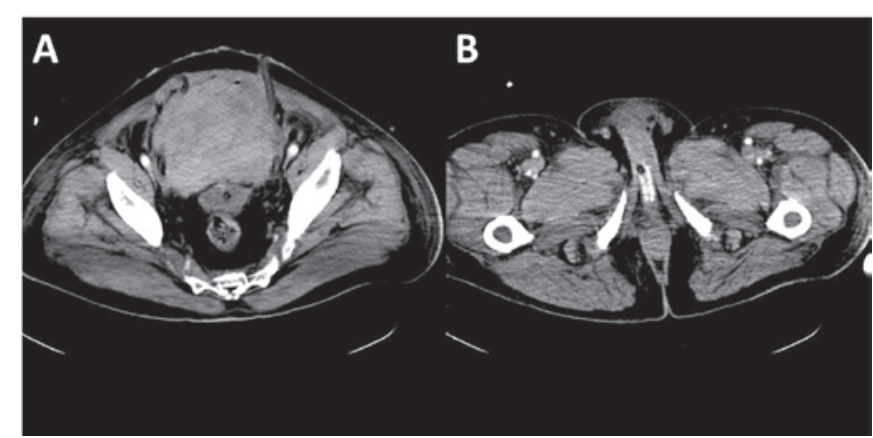

Figure 1. CTA identified (A) a large extraperitoneal hematoma and (B) two active bleeding sites close to the urethrovesical anastomosis (white arrow). CTA, computed tomography angiography.

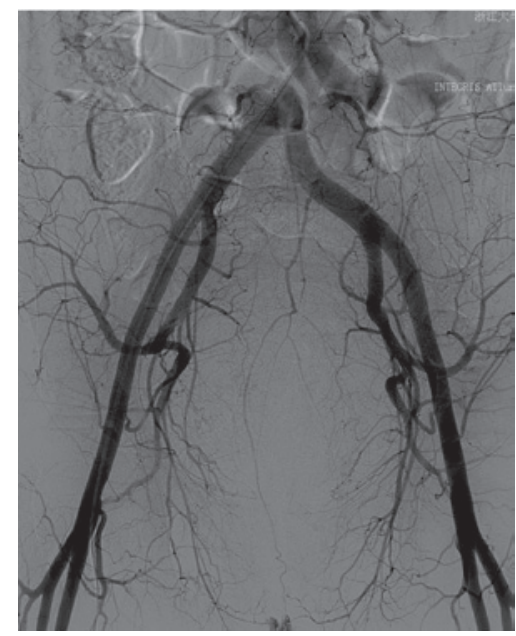

Figure 2. Lower abdominal aorta DSA reveals contrast extravasation from branches of the bilateral internal iliac artery (white arrow). DSA, digital subtraction angiography.

follow-up, the patient had recovered well, regained excellent urinary continence and the pelvic hematoma was absorbed using ultrasound examination.

\section{Discussion}

Historically, major bleeding has been a significant problem associated with radical retropubic prostatectomy. Since the anatomy of the dorsal venous complex and a technique for its early control during radical retropubic prostatectomy were described (1), the incidence of intraoperative and postoperative bleeding has decreased. Life-threatening hemorrhage following a radical prostatectomy is a rare event $(2,3)$. When conservative measures are unable to stop the bleeding, more invasive measures, including open surgical exploration or bilateral extraperitoneal internal iliac ligation have been proposed $(3,4)$.

Although open surgical exploration has been the standard treatment in this situation, there is a continuing search for a minimally invasive procedure to reduce complications. Transcatheter arterial embolization (TAE) has gained an increasing role in controlling life-threatening hemorrhage

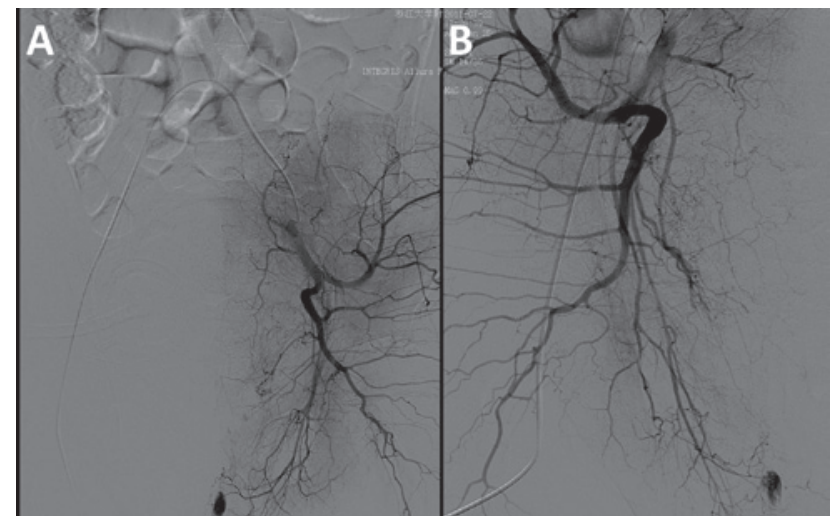

Figure 3. Extravasation from branches of (A) the left and (B) the right internal iliac arteries.. Both were identified using superselective angiography (white arrows).

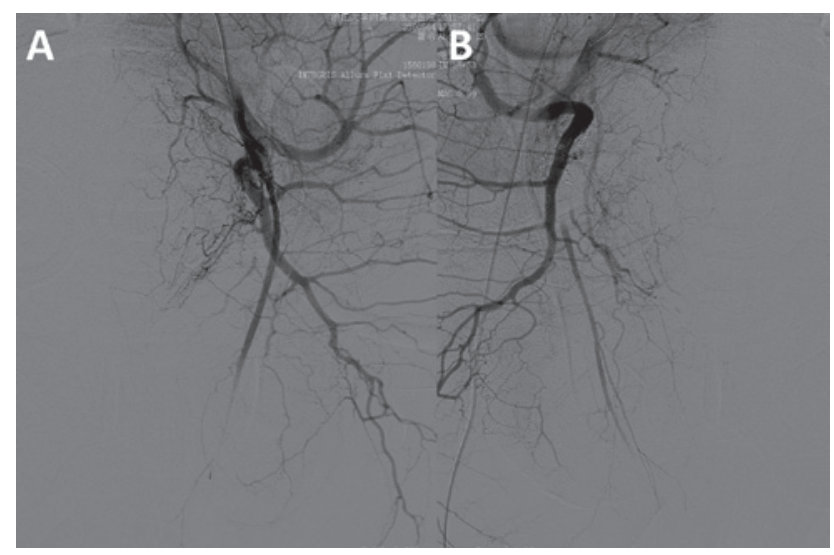

Figure 4. Superselective embolization immediately terminated the extravasation from branches of (A) the left and (B) the right internal iliac arteries.

from various bleeding sites. Since the introduction of internal iliac embolization in 1974 by Hald and Mygind (5), it has been successfully used in controlling pelvic bleeding. Appleton et al (6) reported their experience with embolization of the internal iliac artery in eight patients with severe bladder hemorrhage and in two with severe bleeding following a prostatectomy. Effective control of the bleeding was achieved in six patients with bladder hemorrhage and in the two patients with postprostatectomy bleeding. Nabi et al (7) described the successful management of intractable hematuria due to bladder and prostatic tumor using embolization of the anterior division of the internal iliac artery with no recurrence at a mean follow-up of 22 months. Effective embolization of prostatic vessels following transurethral resection of the prostate (TURP) or prostatic biopsy has also been reported (8-10).

With the continuous development of microcatheters, embolic materials and DSA, superselective embolization has become a possible management technique for the treatment of severe hemorrhage. De Berardinis et al (11) reported a successful case of superselective embolization of the bladder arteries in the treatment of a severe bladder hemorrhage due 
to radiation cystitis following radiotherapy. Superselective embolization has also been conducted in 2 cases of a pseudoaneurysm of the internal pudendal artery with arteriovenous fistula following extraperitoneal laparoscopic radical prostatectomy (12). Jeong et al (13) also described the successful treatment of 4 patients who had severe immediate postoperative bleeding following radical prostatectomy using superselective embolization. In the present study, superselective embolization was conducted by introducing a microcatheter tracker $(2.5 \mathrm{Fr})$ with a guide wire $(0.014$ inch) into the branches of the internal iliac arteries. Non-absorbable microcoils were used as embolization material.

When managing postoperative bleeding following a radical prostatectomy, another important factor to consider is the preservation of urethrovesical anastomosis. In the present study, if open surgical exploration had been used, reworking of the urethrovesical anastomosis would have been extremely difficult. This is due to the severe inflammation and edema that was identified on the eighth postoperative day and the active bleeding sites which are close to the urethrovesical anastomosis. Therefore, we selected the TAE technique to maintain the urethrovesical anastomosis. At 6 months follow-up, the patient recovered well and regained excellent urinary continence.

Compared to selective embolization and other methods (14), the advantages of superselective embolization include a lower recurrence rate with regards to bleeding and fewer side-effects, including postembolization gluteal pain, claudication and tissue necrosis, which require necessitating frequent morphine injections (15). Superselective embolization not only immediately controls the problems associated with severe hemorrhage, but also minimizes the complications.

In conclusion, in the present study, we described a case in which superselective embolization was used to control a severe hemorrhage, which occurred following radical prostatectomy. We concluded that a rapid diagnosis by CTA and an early superselective embolization of the internal iliac artery should be considered as the treatment of choice in severe hemorrhage cases following radical prostatectomy.

\section{References}

1. Reiner WG and Walsh PC: An anatomical approach to the surgical management of the dorsal vein and Santorini's plexus during radical retropubic surgery. J Urol 121: 198-200, 1979.

2. Hedican SP and Walsh PC: Postoperative bleeding following radical retropubic prostatectomy. J Urol 152: 1181-1183, 1994.

3. Kaufman JD and Lepor H: Reoperation versus observation in men with major bleeding after radical retropubic prostatectomy. Urology 66: 561-565, 2005.

4. Rao MS, Rao KM, Vaidyanathan S, et al: Massive venous hemorrhage after bilateral internal iliac artery ligation following retropubic prostatectomy. Eur Urol 4: 465-467, 1978.

5. Hald T and Mygind T: Control of life-threatening vesical hemorrhage by unilateral hypogastric artery muscle embolization. J Urol 112: 60-63, 1974.

6. Appleton DS, Sibley GN and Doyle PT: Internal iliac artery embolisation for the control of severe bladder and prostate haemorrhage. Br J Urol 61: 45-47, 1988.

7. Nabi G, Sheikh N, Greene D and Marsh R: Therapeutic transcatheter arterial embolization in the management of intractable haemorrhage from pelvic urological malignancies: preliminary experience and long-term follow-up. BJU Int 92: 245-247, 2003.

8. Suzuki Y, Nakada T, Ishigooka M, et al: Pelvic arteriovenous aneurysm caused by transurethral resection of the prostate: successful management by intra-arterial embolization. Urol Int 60: 191-193, 1998.

9. Kaneko T, Suzuki T, Matsushita N and Yoshida I: Transcatheter arterial embolization for bleeding of prostatic artery after prostate biopsy. Nihon Hinyokika Gakkai Zasshi 94: 693-695, 2003.

10. Barbieri A, Simonazzi M, Marcato C, et al: Massive hematuria after transurethral resection of the prostate: management by intraarterial embolization. Urol Int 69: 318-320, 2002.

11. De Berardinis E, Vicini P, Salvatori F, Sciarra A, Gentile V and Di Silverio F: Superselective embolization of bladder arteries in the treatment of intractable bladder haemorrhage. Int J Urol 12: 503-505, 2005.

12. Lopes RI, Mitre AI, Rocha FT, Piovesan AC, da Costa OF and Karakhanian W: Case report: late recurrent hematuria following laparoscopic radical prostatectomy may predict internal pudendal artery pseudoaneurysm and arteriovenous fistula. J Endourol 23: 297-299, 2009.

13. Jeong CW, Park YH, Ku JH, Kwak C and Kim HH: Minimally invasive management of postoperative bleeding after radical prostatectomy: transarterial embolization. J Endourol 24: 1529-1533, 2010.

14. Pisco JM, Martins JM and Correia MG: Internal iliac artery: embolization to control hemorrhage from pelvic neoplasms. Radiology 172: 337-339, 1989.

15. Greenstein A, Merimsky E, Papo J and Braf Z: Persistent gluteal pain after embolization of the hypogastric arteries. An unexpected complication. J Urol (Paris) 89: 595-596, 1983. 